\title{
Internet: de la rapidez a la inmediatez
}

Nuria Monfort Sánchez

Periodista

La llegada de Internet a los medios de comunicación ha cambiado radicalmente las rutinas, ha revolucionado la relación entre unos y otros y ha derrumbado las barreras físicas y temporales. En este sentido, la convivencia entre la radio y las agencias de noticias, hasta la llegada de Internet, estaba lastrada por la acusación, ciertamente fundada, de que las segundas trabajaban con la mente puesta en los periódicos. Efectivamente, los redactores de las agencias de información escriben noticias demasiado largas para los medios audiovisuales. Pero, además de eso, en la galaxia muy muy lejana del mundo offline, eran culpables de no tener en cuenta la franja horaria de los informativos de mediodía para enviar sus noticias.

Las agencias de noticias cubren aquellas convocatorias que, a pesar de parecer interesantes, las radios normalmente no pueden incluir en su agenda por falta de personal. El problema es que estas noticias, a excepción de actos programados a primera hora de la mañana, suelen salir en el teletipo cuando los informativos ya están editados o incluso ya finalizados.

Es cierto que existe una determinada figura, la del avance, que consiste en enviar, prácticamente al finalizar la rueda de prensa o acto, un titular y un par de párrafos que contengan lo esencial de la información, pero también lo es que entonces se reservaba para acontecimientos verdaderamente relevantes. Con la introducción en los periódicos de las ediciones digitales las agencias se vieron obligadas a transmitir avances de noticias no tan trascendentes. Ya no era necesario que dimitiera un president de la Generalitat o que hubiera una crisis de gobierno para considerarlo materia de avance. Con que la información 
fuera susceptible de figurar de forma destacada en la edición impresa de los periódicos del día siguiente era suficiente. Así, con la intención de conseguir una firma en las ediciones de los periódicos digitales, las agencias los transmiten cada vez más frecuentemente. Suelen ser noticias de un par de párrafos, tres a lo sumo, que permiten a las radios incluirlas en los informativos aunque sea como un breve.

También es cierto que las propias ediciones digitales, tanto de los periódicos como de los medios audiovisuales, se han convertido en competidores directos de las agencias de noticias, ya que publican las noticias incluso con más rapidez. Y esto también ha servido de acicate para ganar en celeridad.

Paralelamente, las secciones tipo Eskup de El País, que han reproducido prácticamente todos los diarios en sus ediciones digitales, han conseguido desplazar claramente a las agencias de noticias en determinados acontecimientos, puesto que permiten seguirlos prácticamente minuto a minuto. Por ejemplo, en el juicio del expresidente de la Generalitat, Francisco Camps, en el Tribunal Superior de Justicia de la Comunitat Valenciana por la causa separada de los trajes del caso Gürtel, era mucho más ágil seguir la información a través de lo que relataban en este tipo de secciones los redactores de los diarios desplazados en el tribunal que mediante los avances y resúmenes que ofrecían las agencias de noticias.

Pero Internet va más allá en la exigencia de la rapidez, o más bien, llegados a este punto, de la inmediatez. Y ahí está el hecho de que la mayor parte de las instituciones dispone de una cuenta de Twitter, en la que en ocasiones, informa de determinadas cuestiones antes de hacerlo por canales más usuales, como el correo electrónico, lo que obliga al periodista a revisar frecuentemente no sólo la bandeja de entrada de su email, sino las actualizaciones de las redes sociales.

Además, el redactor compite ya no únicamente con los colegas de otros medios de comunicación, sino con las propias fuentes de la noticia, puesto que cualquier ciudadano que quiera estar informado de primera mano obviando el filtro que suponen los medios solo tiene que suscribirse a los perfiles de partidos políticos o instituciones.

En este sentido, solo hay que remitirse a la disputa por alcanzar la Casa Blanca que libraron en noviembre del pasado año el demócrata Barack Obama y el republicano Mitt Romney, en el que hubo claramente otro ganador: Twitter, que de red social pasó en un segundo a ser el más potente medio de comunicación. El tuit en el que el propio Obama proclamó su victoria se ha convertido en el más 'retuiteado' de la historia. El mensaje «Four more years» consiguió hasta las nueve de la mañana hora española, más de 498.000 retuits. Y desbancó a los medios de comunicación (televisión, radio) que tradicionalmente recogen las primeras palabras de un vencedor electoral.

Se trata, además, de un nuevo tipo de audiencia. El destinatario de la información demanda que sea veraz, trabajada y de calidad, pero a la vez instantánea, 
porque el nuevo cóctel está aderezado con la irrupción de los smartphones, que permiten a las personas interactuar estén donde estén, ser los primeros en saber de la noticia sea la hora que sea, tener todas las posibilidades en su propia mano, sin tener que esperar a llegar a casa o a la oficina y ponerse delante del ordenador.

En definitiva, hemos pasado de los de los consumidores del 1.0, a los prosumidores en el 2.0: de reactivos, a proactivos. La gran diferencia es la bidireccionalidad de la información, antes llegaban a la red en busca de información, ahora la ven, la comentan, la recomiendan o no, y todo ello desde la misma página de los medios, ante los ojos del periodista que la ha escrito.

Por otro lado, una de las asignaturas pendientes de las agencias de noticias respecto a las radios es, dada la facilidad que actualmente ofrece Internet para enviar datos, la introducción de teletipos con un corte de voz incorporado, dado que todos los redactores trabajan con grabadora digital. Sin embargo, la tendencia sigue siendo centrarse en la prensa escrita. Por ejemplo, en Europa Press, el pasado año se invitó a los redactores a llevar una cámara de fotos a las ruedas de prensa y actos para poder vender fotografías, una vez más, a los periódicos.

\section{Referencia de este artículo}

Monfort Sánchez, Nuria (2013). Internet: de la rapidez a la inmediatez. En: adComunica. Revista Científica de Estrategias, Tendencias e Innovación en Comunicación, $\mathrm{n}^{0} 5$. Castellón: Asociación para el Desarrollo de la Comunicación adComunica, Universidad Complutense de Madrid y Universitat Jaume I, 269271. DOI: http://dx.doi.org/10.6035/2174-0992.2013.5.20. 